\title{
ASSERTIVE COMMUNICATION SKILLS
}

\author{
Maria Daniela Pipaş ${ }^{1}$ \\ Mohammad Jaradat ${ }^{2}$
}

\begin{abstract}
Assertive communication is the ability to speak and interact in a manner that considers and respects the rights and opinions of others while also standing up for your own rights, needs and personal boundaries. Assertive communication skills create opportunities for open discussion with a variety of opinions, needs and choices to be respectfully heard and considered in order to achieve a win-win solution to certain problems. It can strengthen your relationships, reducing stress from conflict and providing you with social support when facing difficult times.
\end{abstract}

Key words: ability, assertiveness, assertive behavior, passive behavior, aggressive behavior, submissive communication

JEL Code : D83, M12

\section{Introduction}

People communicate with each other both verbally and nonverbally. We transmit our thoughts and feelings through words - verbal and nonvebal through body language, tone of voice, facial expressions, gestures and actions. It is important to have an agreement between the two forms of communication. Studies show that when there is a discrepancy between verbal and nonverbal message we tend to believe the second one. Starting from the two forms of communication are three styles of communication in relationships. These styles are called passive, aggressive and assertive. It is known that people use all three styles of communication in a conversation and when the situation requires they address only one style.

"Assertive" is a new term, introduced somewhat abused in Romanian, with an uncertain status of neologism which refers to an assertive person, ambitious, who wants to impose, selfcontrolled.

\section{What does it mean to be assertive?}

It means you can say what you do not agree with in an elegant manner, without being verbally aggressive, without damaging or disturbing, without being placed in a delicate position, leaving room for discussion, but in terms that you took the freedom to "impose."

We are often at home, at work, in society, faced to relate with people who do not communicate as we want, that don't understand the words we say. This inability to communicate leads to frustration, disappointment and sometimes creates a feeling of powerlessness. Form there to shouting, to raise the tone or use harsher words, there is only one step. Those who have experienced some kind of education may not fall into this "sin", using different ways to express dissatisfaction, disagreement or even control the discussion. But what happens to "others"? Well, the others get to say words that they regret later, come across to channel frustration in the form of verbal aggression, often directed towards people nearby that are not necessarily involved directly in the events referred to in the discussion.

\section{What is assertiveness?}

\footnotetext{
1 "Bogdan Vodă" University of Cluj-Napoca, dpipas@yahoo.com

2 "Bogdan Vodă" University of Cluj-Napoca, jaradat_hadi@yahoo.com
} 
Assertiveness is the ability to represent to the world what you really are, to express what you feel, when you feel it necessary. It is the ability to express your feelings and your rights, respecting the feelings and rights of others. Those who have mastered assertiveness are able to reduce interpersonal conflicts in their lives, thus removing a major source of stress for many of us.

Assertive behavior demonstrates respect for self and others, promotes self-disclosure, selfcontrol and positive appreciation of self-worth.

Assertiveness is the most effective way of solving interpersonal problems. Direct communication, openness and honesty allow you to receive messages without distortion, which maintains relations with others.

\section{Understandings of assertiveness}

Lazarus (1973) was the first to identify specific classes of responses in which assertive behavior can be defined: "the ability to say no, the ability to ask favors or make requests, ability to express positive and negative feelings, the ability to initiate, continue and finish a general conversation."

Smith (1975) analysis assertive behavior as a fundamental right of every individual. His concept of freedom has taken a much more extensive liberty than the social-democratic philosophy had: "You have the right to judge your own behavior, thoughts and emotions, to have responsibility for taking behaviors and their consequences."

Lange and Jacubowski (1976) claimed that "assertiveness involves personal rights and expressing thoughts, feelings and beliefs directly, honestly and appropriately, without violating the rights of others".

The most successful definition of this category is made by Rimm and Masters (1979): "Assertive behavior is an interpersonal behavior involving relatively honest and direct expression of thoughts and feelings that are socially appropriate and take into account the feelings and welfare of other people".

Some definitions are attached to the emotional exposure as a key. Wolfe (1982) conceptualizes assertiveness as "expressing any emotion other than a person's anxiety."

Lowrence (1997) extends the concept of assertiveness to "learning ability to adapt behavior to interpersonal situation on demands so that positive consequences are best and negative one minimum."

\section{Assertive style}

Assertive communication style is a combination of passive and aggressive style. This style also requires fairness and power. This characterizes people fighting for their rights but assertive while remaining sensitive to the rights of others and so the fight for what they deserve will not harm anyone. This are people that are relaxed and talk openly about their feelings.

Assertive style of communication requires a balance between what these people want and what others want. The basis of this communication style is open attitude towards oneself and others, and hearing other points of view and respect for others. This communication style is best suited for a good long term relationship. Studies show that people who deal in an assertive style of communication are able to reach an emotional welfare. This communication style allows you to argue your opinion without being aggressive and not feel humiliated.

\section{Components of assertiveness}

The concept of assertiveness was introduced by experts in behavioral therapy, assertiveness claiming to inhibit anxiety and reduce depression. It points out that assertive behavior leads to improved self-image. 
After Lazarus, assertiveness involves four elements:

1. rejecting demands;

2. request favors and making calls;

3. positive and negative feelings;

4. initiation, continuation and conclusion of a general conversation.

They constituted cognitive component involving a certain way of thinking.

The behavioral component of assertiveness includes a series of non-verbal elements such as:

1. Eye contact: an assertive person will look their interlocutor in the eye. Lack of eye contact can send unwanted messages, such as: "I'm not sure what to say" or "I am very afraid";

2. Tone of voice: even the most assertive message will lose its significance if it is expressed with a hushed voice (this will give the impression of uncertainty) or too hard, which could activate depressive behavior on the interlocutor;

3. Stance: assertive posture of a person varies from situation to situation. However, it is estimated that in most cases, the subject must stand right: not too stiff, because it expresses a state of tension, not too relaxed, because others could interpret such a position as disrespectful.

4. Facial expressions: for the message to be assertive naturally, mimicry must be appropriate and congruent with the message content. Otherwise, for example, if someone smiles when he says that something bothers him, the party offers ambiguous information, which alters the meaning of communication.

5. Timing the message: the most effective assertive message loses meaning when taken in the wrong time. Thus, for example, no boss will respond favorably to a request for wage increase, no matter how well made is that made, if an employee approaches you when preparing to appear before a committee of the company's control.

6. Content: even if all other conditions are met, the message does not achieve its purpose if it is too aggressive, with the intention of blaming the other or, conversely, expressed in a very shy and passive way. The content of an assertive message should be narrowly, descriptive and direct.

The concept of assertiveness, relatively new in the Romanian society is "imported" from the Americans and it means, in principle, to say "no" without feeling guilty. More articulate, assertive communication is when you say what you want to say, firmly, spontaneous, honest and direct, keeping your dignity and rights and at the same time, not insulting the other - so without attack him as a person, but referring strictly to his behavior.

Assertiveness is not a natural behavior, we are born with. People behave and communicate in relation to the two primary reactions - to flee or fight - submissive or aggressive. "Naturally, we behave and communicate submissive or aggressive, assertiveness is a way of communication that constitutes a behavior and is educated - so a skill that must be known and then practiced". If we put on a scale of two extremes - submissive and aggressive - assertive behavior is not as we expect, in the middle.

Assertive behavior is much closer to the aggressive one, but aggressive behavior is different in the fact that it does not infringe the rights and freedoms of others. Also it analyzes the behavior of others and not their person.

For example, a manager who enters the office and tells his people: "I am unhappy that you have not reached the targets that we have established. What happened?" behaves assertively, and a manager who says: "Normally. I am not in a day and no one does one thing. Idiots!" has an aggressive behavior.

People whose natural behavior is submissive are those who succeed are the hardest to communicate assertively, because they are afraid all the time and don't have the courage to address a communication so far (close to the other end of the scale) and contrary to their behavior natural settings. If they are the kind of employees that, when they are burdened with additional tasks, say each time: "Well, I will do this too" or "I'm sorry I could not finish everything", will be very 
difficult to tell their boss: "Look, this report must be done by someone else and you gave it to me. I have accomplished my tasks that I have under the job description. It is the fifth time you give me reports that are not what I have to do. If not part of my duties, why do you still argue with me? ".

"Most people are aggressive or submissive, few are assertive," said Dorin Dancu, noting: "Unfortunately, we see looking around us - in Romania at least - that many people fail to communicate assertively. And to the assertiveness is a long way. "

An assertive communication means, first, to know what your needs are and how to get them. Therefore, a communication objective is to win, but to solve problems and to have maximum results. In terms of social or professional relationships, assertive communication is the middle way and involves:

- $\quad$ request of own rights;

- denial of tasks in a simple, direct manner.

Assertiveness is a compromise between a passive communication, where you agree with everything your caller says, and an aggressive one, when counter any reply and have desire to impose.

An assertive communication is an effective adaptation to conflicting situations. In any organization, communication is improved if there is an open, non-aggression or malice dialog.

Assertiveness includes:

- $\quad$ Being able to express your opinions and viewpoints

- $\quad$ To be able to say no without feeling guilty.

- $\quad$ To be able to ask for what you want

- $\quad$ To choose how to live your life without feeling guilt about it

- $\quad$ Being able to take risks when you feel the need

If you feel you lack one or more of the above points, then you may have trouble expressing yourself to the world and to show who you really are.

Very often, you may be afraid to be assertive so as not to disturb anyone or to draw something bad in your life, if you say what you think. Have you ever thought:

- $\quad$ can not say no, because you think I'm selfish."

- no not want to make scenes at work."

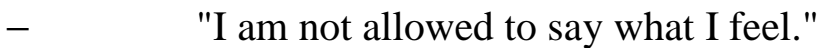

- $\quad$ - $\quad$ "I do not want to offend anyone or anyone to piss me off."

- $\quad$ "If I express my point of view, others will not like me."

Some people confuse assertiveness with aggression, considering that both behaviors imply to express your needs and your rights. The major difference between them is the respect for other people that you meet in the assertive style. They respect themselves and others and always think in terms of "win-win."

Aggressive people use tactics of manipulation, abuse and have no respect for others. The think negative about others and do not take into account the views of others. Most often, the create free conflicts.

Passive people don't know how to communicate their feelings and needs. The fear of conflict so much that they prefer to hide their true feelings and needs, to maintain peace with others. The let others always come out winners in any conflict and this leads to total loss of self esteem.

Assertiveness affect almost all facets of life. People who acquire this skill have less conflict, less stress, therefore, they meet their needs and help others to meet theirs as wall, and also have strong relationships that they can rely on. All these lead to a better mental state and a substantially improved health.

\section{Discover your problems}


To manage to change your non-assertive behavior, you must first recognize the problem. Remember a few situations where you felt that you needed to say what you think, but you feel that you can not, or when you wanted from the heart to say "no" and you said "yes" in the latter, or when you did not say anything while you were ridiculed by someone.

Do you have trouble in accepting constructive criticism?

You are often in a position to say "yes" to requests that you want to say "no", just to not disappoint others?

Do you have trouble expressing differences of opinion over others?

When you do not agree with the others and say that, strange reactions arouse your way through communications?

You feel attacked when someone has a different view from yours?

Answering these questions will help you understand when and why these problems of assertiveness occur. It could be about a shyness in front of the opposite sex, or you may feel intimidated by authority figures.

\section{Build mental scenarios}

Mental practice different scenarios in which you have an assertive speech. If you have not done that, it might take some time, but when you start to practice often it will become second nature to you. Here are some tips to keep in mind when practicing how to be assertive:

- $\quad$ Stay focused on the subject matter and do not complicate things.

- $\quad$ Be polite but firm with that person.

- $\quad$ Listen to what that person says, but remain calm

- $\quad$ Look in the eyes of the person, but do not stare (look at his left eye, and then the right at then at the mouth)

- $\quad$ Do not apologize if it is not necessary

\section{Highlight other person's behavior}

One thing that works when we have a confrontation with someone is trying to emphasize the disturbing behavior of other people, for example to say: "Why raise your voice at me?". The question will be confusing at the moment and it will make him/her lose the thread of thought and to think about his/hers actions. Some people just do not realize when they become aggressive in conversation, and this is a great way to take control in a situation like this.

\section{Five simple steps to assertive behavior}

1. When you approach someone about a behavior change that you want to see in that person, make reference to factual descriptions of the thing that has upset you, and do not affix labels or value judgments. Example: Your friend has delayed 20 minutes when you had to meet to discuss something important. Do not tell him: "You are such an asshole, always late!" But tell him: "We were supposed to meet at 17.30, now it's 17:50 p.m."

2. The same thing is true when describing the effects of behavior. Do not exaggerate and do not judge, just describe! Do not say "You ruined my hole night", but said: "We have less time available to discuss the issue, because to 18.30 I planned something else."

3. Use the word "I". You'll succeed as to focus on what you feel and how you are affected by the behavior of others. If you start with "You", that phrase would be perceived as an attack and the other will maintain the conflict. Do not say: "You must stop!" but, "I would feel better if you did not do that."

4. Here's a formula for success in assertive communication: "When you [the other's behavior], I feel [my feelings]." "When you scream, I feel attacked."

5. A slightly more comprehensive formula for such situations is: "When you [the other's behavior], then [the result of conduct], and I feel [my feelings]. " "When you tell the children they 
can do something I've banned them, then my parent's authority is affected and I feel discredited before them."

\section{THE RIGHT TO ASSERTIVENESS}

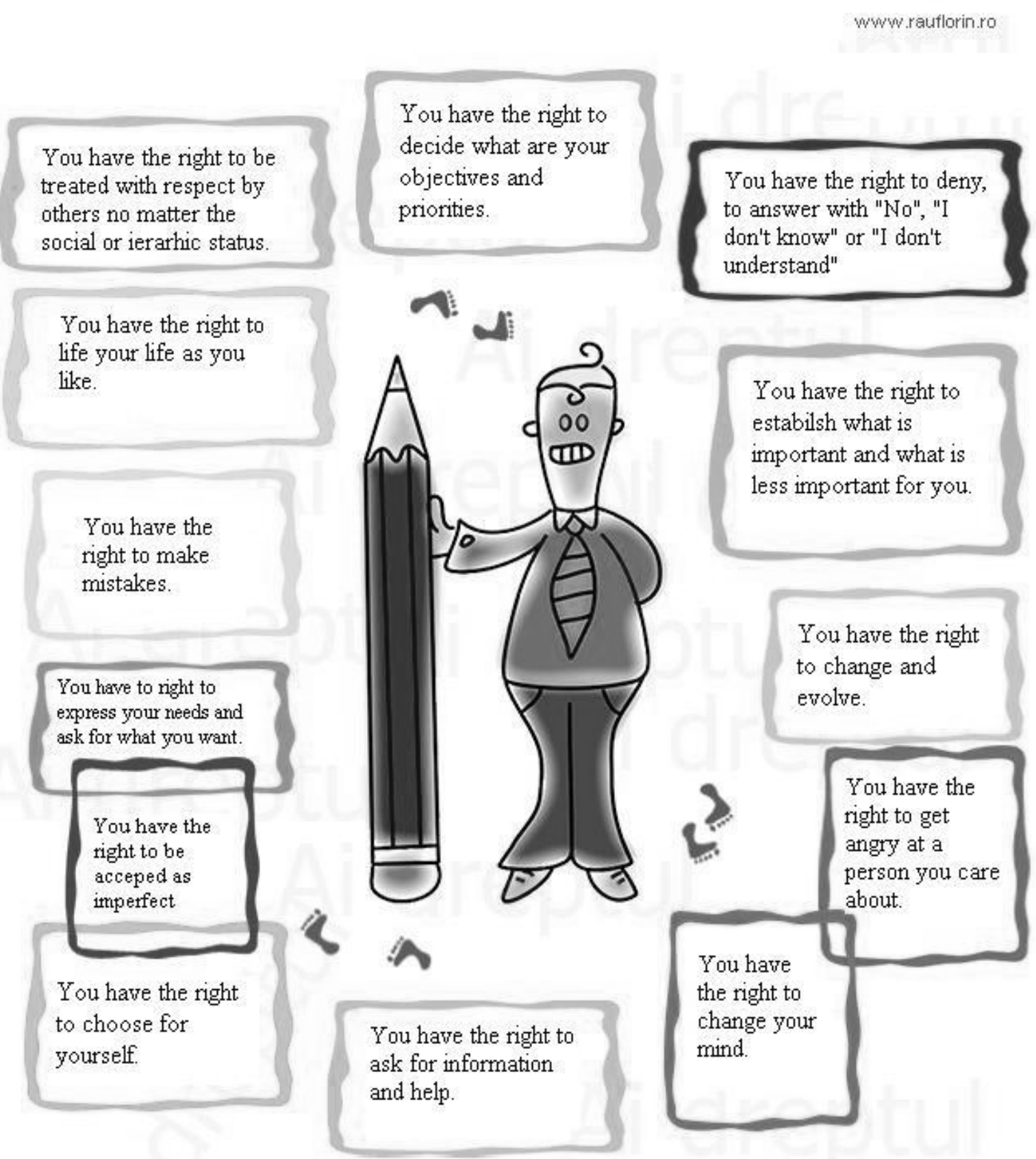

Figure no.1 - The right to assertiveness

( reproduction after www.rauflorin.ro)

Assertiveness does not exist! Says Andy Szekely's trainer

The concept is actually an "American gimmicks" which refers to the courage to call spade in a manner respectful of others. 
Assertiveness does not exist because it is actually a very abstract concept that does not mean almost anything until you see two people who communicate assertively with each other. So, assertiveness is not a thing but a process. It is an object of study as soon as a matter of practice.

Being assertive is to communicate authentically and effectively, while building real longterm relationship.

One way to be contrasted with the assertiveness is aggression. I mean, to say what you want to say without caring about the reaction of the other, dominating him mentally, emotionally and sometimes physically.

Therefore, assertiveness is an important condition of your internal state - the way you feel when you have an assertive behavior against somebody. It is best to choose the moments when you feel a very good inner balance. If you have hard feelings or emotions to the person it is better to wait a little before exposing an assertive behavior.

As a method, one can practice assertive behavior in 7 steps, as it is described as the acronym below.

\section{Attention}

Capture attention in a way that is of interest to listen to each other. In this way you have wide open space to negotiate and avoid rejection reaction that can occur even when you tell the other that you want to "give a feedback". Most people hate to receive unsolicited feedback, but accept it because it is "politically correct".

\section{Situation}

Describe the situation briefly. Specify when, where and under what conditions the interaction occurs. Be brief and specific.

\section{Emotion}

Tell yourself what is for the emotional impact of the situation. Be also very concise.

\section{Reaction}

Explain the behavioral response as a result of the emotion you feel. Make reference to the consequences of emotion felt.

\section{Test}

Test your level of concern of the party by offering them a solution that you think or asking his opinion. Do not start with the idea that your solution is the only right one. fact, if the solution comes from him, he is more likely to put into practice, according to persuasion law called the law of consistency.

\section{Involvement}

Get involved with the other in finding a method for monitoring the progress of the new behavior. Ask him what he could do because it requires that the new behavior to be easily reproducible, and to give you feedback to help more further.

\section{Valorization}

Thank the interlocutor for listening and that he is willing to accept the new terms. Show him that for your relationship with him is valuable and important.

\section{Conclusions}

Assertiveness is a useful communications tool. Its application is contextual and appropriate in all situations. Using sudden assertiveness may be perceived as an act of aggression by others. 
There is also no guarantee of success, even when you use assertive communication styles appropriately.

Both in literature of specialty and in the literature usual, the term of assertive behavior was faced with what we understand by the term "aggression" and "passivity." Assertive behavior is often considered an opponent of aggressive behavior and passivity is not clearly delineated by assertiveness. Thus, cognitive-behavioral professionals need support in a first phase of restructuring the way of thinking, through combating negative thoughts, dysfunctional or underlying lack of confidence in the ability to express their views. That simply means that human exposure to what assertive behavior is \& the examples of behavior will not be available to get from a pattern of behavioral change.

\section{References}

1. Brehm Sharon S. Kassin Saul M., 2008. Social Psychology, Fifth Edition, Indiana University Bloomington, Williams College Steven Fein, Houghton Mifflin Company, Boston U.S.A.

2. Coman Alina, 2004. Comunicarea empatică în rezolvarea conflictelor: semnalele nonverbale în: Septimiu CHELCEA (coord.). Comunicarea nonverbală în spaţiul public. Bucureşti: Editura Tritonic, p.167-184.

3. Coman Alina, 2008. Tehnici de comunicare. Proceduri şi mecanisme psihosociale. Bucureşti, Editura C.H.Beck.

4. Nelson-Jones, Richard, 1996. Relating Skills. Redwood Books, Trowbridge, Wiltshire.

5. Pease Allan, Garner Alan, 1999. Limbajul vorbirii. Arta conversaţiei. Bucureşti: Editura Polimark

6. Perlow Leslie, 2003. When You Say Yes But Mean No: How Silencing Conflict Wrecks Relationships and Companies .... and What You Can Do About It. New York: Crown Business.

7. http://www.andyszekely.ro/blog/comunica-asertiv-nu-agresiv

8. http://www.tmi.ro/despre-tmi/consultanti/dorin-dancu.html

9. http://EzineArticles.com/?expert=Lee_Hopkins Assertive Communication - 6 Tips For Effective Use, By Lee Hopkins. 